\title{
Tau interacts with the C-terminal region of a-synuclein, promoting formation of toxic aggregates with distinct molecular conformations
}

\author{
Anvesh K. R. Dasari ${ }^{\dagger}$, Rakez Kayed", Sungsool Wi§, Kwang Hun Lim ${ }^{\dagger},{ }^{*}$ \\ †Department of Chemistry, East Carolina University, Grenville, NC 27858, USA. \\ IDepartments of Neurology, Neuroscience and Cell Biology, University of Texas Medical Branch, \\ Galveston, TX, 77555, USA. \\ $\S$ Center of Interdisciplinary Magnetic Resonance (CIMAR), National High Magnetic Field \\ Laboratory (NHMFL), 1800 East, Paul Dirac Dr., Tallahassee, FL 32310, USA.
}

\begin{abstract}
An increasing body of evidence suggests that aggregation-prone proteins associated with various neurodegenerative diseases synergistically promote their mutual aggregation, leading to the cooccurrence of multiple neurodegenerative diseases in the same patient. Here we investigated molecular basis of synergistic interactions between the two pathological proteins, tau and asynuclein, using various biophysical techniques including transmission electron microscopy (TEM), circular dichroism (CD), and solution and solid-state NMR. Our biophysical analyses of a-synuclein aggregation in the absence and presence of tau reveal that tau monomers promote the formation of a-synuclein oligomers, subsequently fibril formation. Solution NMR results also indicate that monomeric forms of tau selectively interact with the C-terminal region of asynuclein monomer, accelerating a-synuclein aggregation. In addition, a combined use of TEM and solid-state NMR spectroscopy reveals that the synergistic interactions lead to the formation of toxic $a$-synuclein aggregates with distinct morphology and molecular conformation. The filamentous $\mathbf{a}$-synuclein aggregates as well as $\mathbf{a}$-synuclein monomers were also able to induce tau aggregation.
\end{abstract}

\section{Graphical Abstract}

\footnotetext{
*Corresponding Author: limk@ecu.edu.

Author Contributions

The manuscript was written through contributions of all authors. All authors have given approval to the final version of the manuscript.

Supporting Information.

Amino acid sequences of a-synuclein and tau. TEM images of a-synuclein aggregates. ThT fluorescence. CD spectra of a mixture of tau and a-synuclein. An enlarged ${ }^{1} \mathrm{H} /{ }^{15} \mathrm{~N}$ HSQC spectrum. NMR signal intensity changes of a-synuclein upon additions of tau.

The following files are available free of charge.

The authors declare no competing financial interest.

Accession Codes

a-synuclein: UniProtKB entry P37840

tau: UniProtKB entry P10636
} 


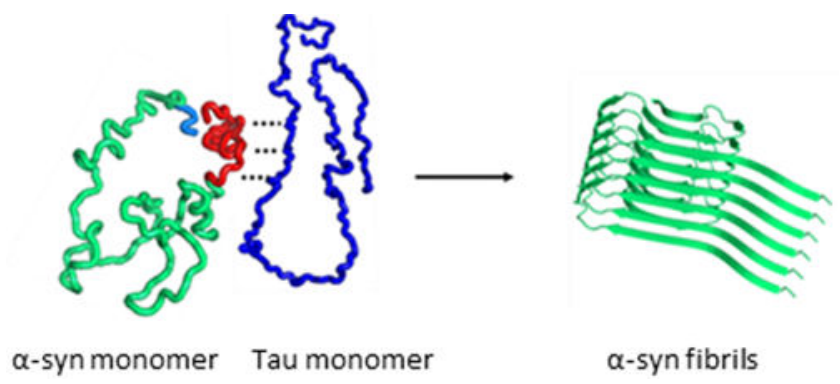

\section{Keywords}

a-synuclein; tau; solid-state NMR; transmission electron microscopy; filament; cross-seeding

\section{Introduction}

Abnormal accumulation of various misfolded proteins is associated with numerous debilitating neurodegenerative diseases. Traditionally, intracellular deposition of misfolded a-synuclein is a hallmark of Parkinson's disease, ${ }^{1}$ while Alzheimer's diseases is characterized by intraneuronal accumulation of filamentous tau. ${ }^{2}$ There is, however, increasing evidence that suggests $a$-synuclein and tau pathologies are significantly overlapped. ${ }^{3,}$ 4, 5 Firstly, co-deposition of a-synuclein and tau was observed in Alzheimer's disease and related dementias (ADRD). ${ }^{3,4,5,6}$ For example, misfolded $a$-synuclein aggregates were found in more than $50 \%$ of Alzheimer's disease (AD), Down's syndrome, and familial AD cases. ${ }^{7,8,9}$ Tau aggregates were also detected in patients with Parkinson's disease dementia and the amount of tau aggregates is correlated well with cognitive decline. ${ }^{5,10}$ Secondly, recent studies showed that $a$-synuclein and tau can synergistically promote their mutual aggregation, ${ }^{11}$ suggesting that synergistic interactions between the two pathological proteins might exacerbate ADRD pathology. In particular, misfolded asynuclein aggregates with distinct molecular conformations (strains) were shown to differentially induce the formation of distinct tau strains in vivo (cross-seeding). ${ }^{12}$ These results indicate that $\mathrm{AD}$ and $\mathrm{PD}$ pathologies are significantly overlapped presumably due to synergistic interactions between $a$-synuclein and tau.

a-synuclein is a 140-residue intrinsically disordered protein that is primarily localized at presynaptic terminals of the central nervous systems (CNS). The presynaptic protein consists of three main regions: the amphipathic N-terminal (1-64), hydrophobic non-A $\beta$-component (NAC) (65-95), and acidic C-terminal region (96-140) (Figure S1a). The hydrophobic NAC region that plays a central role in a-synuclein aggregation was shown to be protected by long-range interactions between the $\mathrm{N}$ - and $\mathrm{C}$-terminal regions in the natively disordered state of a-synuclein. ${ }^{13,} 14$ Thus, perturbations of the long-range interactions by single-point mutations and interactions with small molecules led to the formation of filamentous $a$ synuclein aggregates. ${ }^{15}, 16,17$

Tau is an intrinsically disordered 352-441 residue microtubule-binding protein that is abundantly present in the central nervous system (Figure S1b). Intraneuronal accumulation of filamentous tau protein is a hallmark of a wide range of neurodegenerative diseases such 
as Alzheimer's diseases (AD) and frontotemporal dementia, collectively termed tauopathy.

2, 18 The natively unfolded protein is highly soluble under the physiological condition and co-effectors such as glycosaminoglycan are required to induce tau aggregation. It is, therefore, highly plausible that misfolded a-synuclein strains can promote tau aggregation through direct interactions in vivo (cross-seeding), as demonstrated in neuron and animal models. ${ }^{11,12,19}$

Despite the growing evidence of the synergistic interactions between the two proteins, molecular basis for the synergistic aggregation of the two proteins remains largely unknown. For example, it is unclear whether the two proteins aggregate at the same time due to the synergistic interactions between the two monomeric proteins, or one of the proteins may form misfolded aggregates first, which can then induce aggregation of the other protein. In this study, we systematically investigated aggregation process of the mixtures of full-length tau (2N4R) and $a$-synuclein using various biophysical techniques including transmission electron microscopy (TEM), circular dichroism (CD), and solution and solid-state NMR spectroscopy. Our combined biophysical analyses of the aggregation process revealed that monomeric forms of tau selectively interact with the $\mathrm{C}$-terminal region of a-synuclein, leading to the formation of distinct filamentous aggregates with different molecular conformations. The misfolded $a$-synuclein aggregates as well as $\mathbf{a}$-synuclein monomers were also able to induce tau aggregation.

\section{Experimental Methods}

\section{Protein expression.}

The DNA plasmids of a-synuclein (UniProtKB entry P37840) and tau (UniProtKB entry P10636) were gifts from Michael J Fox Foundation MJFF (pET21a, Addgene plasmid \# 51486) and from Dr. Smet-Nocca (pET15b, Université de Lille, Sciences et Technologies, France), respectively. Wild-type a-synuclein was expressed in BL21 (DE3) E. coli, and was purified as previously described. ${ }^{20}$ Briefly, overexpressed proteins in the soluble fraction of the sonicated lysates were extracted using ammonium sulfate precipitation methods (50\%). The precipitates were resuspended with deionized water and purified using anion exchange Q column followed by size-exclusion gel-filtration chromatography using a HiLoad 16/600 Superdex 75 column (GE Healthcare, Piscataway, NJ). The purification steps were all carried out at $4{ }^{\circ} \mathrm{C}$ to minimize protein aggregation.

The recombinant full-length tau protein (2N4R) was expressed in BL21 (DE3) E. coli strain and was purified as previously described. ${ }^{21}$ Briefly, tau expression was induced with $1 \mathrm{mM}$ Isopropyl $\beta$-D-1-thiogalactopyranoside (IPTG), and the cells were grown at $37^{\circ} \mathrm{C}$ for additional $3-4$ hours. Cells were harvested by centrifugation and sonicated. The soluble fraction of the sonicated lysates was boiled at $80{ }^{\circ} \mathrm{C}$ for 20 minutes. White precipitates were removed by centrifugation, and the supernatant was purified using cation exchange SP column followed by size-exclusion gel-filtration chromatography using a HiLoad 16/600 Superdex 200 column (GE Healthcare, Piscataway, NJ). 


\section{Aggregation assays.}

a-synuclein $(0.15-1.1 \mathrm{mg} / \mathrm{ml})$ in the absence and presence of tau $(0.15-2.2 \mathrm{mg} / \mathrm{ml})$ are incubated in $10 \mathrm{mM}$ phosphate buffer $(\mathrm{pH} 7.4)$ at $37^{\circ} \mathrm{C}$ under constant agitation at $250 \mathrm{rpm}$. Prior to the incubation, the protein samples were filtered using a $0.22 \mu \mathrm{m}$ membrane filter to remove any preformed aggregates. Aggregation kinetics was monitored by measuring optical density (O. D.) at $400 \mathrm{~nm}$ and by thioflavin T (ThT) fluorescence measurement.

\section{Circular dichroism (CD) Spectroscopy.}

The CD spectra were recorded by scanning from $260 \mathrm{~nm}$ to $190 \mathrm{~nm}$ on a Jasco J-815 spectropolarimeter (Easton, MD) using a $1 \mathrm{~mm}$ path length Suprasil quartz cell at pH 7.4. The protein samples were pre-equilibrated at $20^{\circ} \mathrm{C}$ for $5 \mathrm{~min}$ before acquisitions.

\section{Thioflavin T (ThT) fluorescence.}

For the fluorescence measurements, $50 \mu \mathrm{L}$ of $1 \mathrm{mM}$ ThT in PBS buffer ( $\mathrm{pH}$ 7.4) was mixed with $100-200 \mu \mathrm{L}$ of protein solutions. The emission spectra were recorded with an excitation at $440 \mathrm{~nm}$.

\section{Solution NMR spectroscopy.}

NMR experiments were carried out on a Varian/Agilent $800 \mathrm{MHz}$ instrument equipped with a cryogenic probe. NMR data were processed using the software NMRPipe ${ }^{22}$ and the processed data were analyzed using the software NMRView ${ }^{23}$. The $2 \mathrm{D}^{1} \mathrm{H}_{-}{ }^{15} \mathrm{~N} H S Q C$ and ${ }^{15} \mathrm{~N}$ transverse relaxation $\left(\mathrm{R}_{2}\right) \mathrm{NMR}$ experiments were carried out at $15^{\circ} \mathrm{C}$. For the ${ }^{15} \mathrm{~N} \mathrm{R}_{2}$ experiments, NMR spectra were acquired in an interleaved fashion with relaxation delays (in seconds) of $0.01,0.03,0.05,0.07,0.11,0.16,0.25,0.35$, and 0.45 .

\section{Solid-state NMR spectroscopy.}

Solid-state NMR spectra were recorded using Bruker $800 \mathrm{MHz}$ spectrometer equipped with a $1.3 \mathrm{~mm}$ MAS probe. Cross-polarization $(\mathrm{CP})$ based two-dimensional ${ }^{13} \mathrm{C}-{ }^{13} \mathrm{C}$ solid-state NMR spectra were acquired using a dipolar assist rotational resonance (DARR) ${ }^{24}$ at spinning frequency of $13 \mathrm{kHz}$. A linear amplitude ramp on the ${ }^{1} \mathrm{H}$ channel was used for the ${ }^{1} \mathrm{H} /{ }^{13} \mathrm{C}$ cross-polarization with a contact time of $0.7 \mathrm{~ms}$.

The $90^{\circ}$ pulse-lengths for ${ }^{1} \mathrm{H}$ and ${ }^{13} \mathrm{C}$ were 2.1 and $5 \mu$ s, respectively, and the SPINAL-64 (small phase incremental alternation with 64 steps) decoupling scheme ${ }^{25}$ was employed with an rf field strength of $90 \mathrm{kHz}$. For the 2D correlation NMR spectra, complex data points of $1024 \times 290$ were collected with an acquisition delay of $3 \mathrm{sec}$.

TEM.

The protein samples $(1-2 \mathrm{mg} / \mathrm{ml})$ incubated at various incubation times were diluted 10 times, and a $5 \mu \mathrm{L}$ droplet of the diluted sample was placed on formvar/carbon coated copper 400 mesh grids for $30 \mathrm{~s}$ and excess solution was blotted off using a filter paper. Grids were washed with $10 \mu \mathrm{L}$ of $1 \%$ uranyl acetate solution and stained with another $10 \mu \mathrm{L}$ of $1 \%$ uranyl acetate solution for $30 \mathrm{~s}$. The excess staining solution was blotted off with a filter 
paper and the grids were air-dried. TEM images were collected using Philips CM12

Transmission Electron Microscope at $80 \mathrm{kV}$.

\section{Cell viability MTT assay}

Cells were plated (96-well clear bottom black plates) at a density of 10,000-15,000 cells/ well one day before the treatment to let the cell attach to the surface. All the protein samples were filter-sterilized before incubating at $37^{\circ} \mathrm{C}$. Fibrils were collected by centrifugation and washed twice with sterile phosphate buffer and resuspended in complete growth medium (1:1 mixture of EMEM and F12 medium with 10\% fetal bovine serum and 1\% Pen-Strep). Cell medium from wells was replaced with protein solution in complete growth medium and incubated at $37{ }^{\circ} \mathrm{C}$ in $5 \% \mathrm{CO}_{2}$ for one day. All protein solutions were tested in duplicate at three dilutions. Blanks were prepared by adding the complete growth medium to the wells with no cells.

\section{Results}

\section{Tau promotes the formation of a-synuclein aggregates.}

In order to examine the effect of tau on $a$-synuclein aggregation, $a$-synuclein was incubated in phosphate buffer $\left(10 \mathrm{mM}\right.$ potassium phosphate, $\mathrm{pH}$ 7.4) under constant agitation at $37^{\circ} \mathrm{C}$ in the absence and presence of tau. Aggregation kinetics of the pure proteins and mixtures of the two proteins was monitored with turbidity measurements at $400 \mathrm{~nm}$ (Figure 1). Kinetic analyses of the protein aggregation reveal that the pure tau and a-synuclein do not form aggregates during the first three days of incubation. On the contrary, protein aggregation is greatly enhanced for the mixtures of the two proteins, strongly suggesting the presence of synergistic aggregations.

The protein samples incubated for one day were investigated using TEM to examine morphology of the aggregates. Although fibrillar aggregates were not observed in pure asynuclein incubated for one day in Figure 1, the TEM image revealed that $a$-synuclein forms annular oligomers after one day of incubation (Figure 2a), as observed in previous studies $^{26,27}$, while no oligomers were observed for pure tau (Figure 2b). On the contrary, filamentous aggregates were detected for the mixtures of the two proteins (Figure $2 \mathrm{c}$ and Figure S2). An enhanced thioflavin T (ThT) fluorescence was also observed for the mixture incubated for one day at $37^{\circ} \mathrm{C}$, supporting the presence of filamentous aggregates in the mixture (Figure S3).

The enhanced aggregation kinetics of the mixture of the two proteins clearly indicates that one of the proteins or both proteins promote the formation of filamentous aggregates. Additional experiments were carried out at different concentrations to confirm the crossseeding activity of tau. A lower protein concentration of a-synuclein $(10 \mu \mathrm{M})$ and tau (3 $\mu \mathrm{M}$ ) was used to probe an early stage of aggregation using CD spectroscopy (Figure 3 ). The CD spectra of the two monomeric proteins (Figure 3a and 3b) exhibit a minimum at $\sim 196$ $\mathrm{nm}$, which is characteristics of disordered proteins. The $\mathrm{CD}$ spectrum for the mixture of the two proteins (a-synuclein and tau) at a molar of ratio of 1:0.3 (Figure 3c) is also identical to 
the sum of those for the two monomeric proteins, suggesting that the two proteins are largely unfolded in the mixture like the native state of the two proteins (Figure S4).

After two days of incubation, the CD signal at $196 \mathrm{~nm}$ decreases in the mixture, while the signal grows in intensity at $\sim 215 \mathrm{~nm}$. The change in the CD signal for the mixture most likely originate from the oligomerization, and the TEM image of the mixture confirms the formation of oligomers (Figure S5). The CD spectra in Figure 3c were analyzed using the software $\mathrm{CDpro}^{28}$ to estimate secondary structures at different incubation times (Table S1). During the aggregation process, relative content of disordered regions continues to decrease, while $\beta$-structures are gradually developed. In addition, substantial amount of helix and turn was observed after two days of incubation, suggesting the presence of helical intermediate states that were observed in a previous study ${ }^{29}$.

The CD spectra for the pure monomeric proteins in Figure $3 \mathrm{a}$ and $3 \mathrm{~b}$ remain unchanged, suggesting that the oligomerization is promoted by synergistic interactions between the two proteins. The similar conformational changes were also observed for the mixtures with lower relative concentrations of tau at molar ratios of 10:1 (Figure S6) and 100:1 (Figure S7). These CD results of the mixtures with different molar ratios clearly suggest that monomeric forms of tau promote a-synuclein oligomerization, and subsequently filament formation.

\section{Cross-seeding activity of a-synuclein.}

Our combined analyses of co-incubation of monomeric forms of a-synuclein and tau revealed that tau monomers promote $a$-synuclein aggregation. In order to investigate whether a-synuclein also promotes tau aggregation, $\mathrm{CD}$ spectroscopy was used to probe tau aggregation in the presence of $a$-synuclein monomer and $a$-synuclein aggregates derived by a mixture of the two proteins with a-synuclein to tau molar ratio of 10:1 (Figure 4). The CD signals for the pure tau $(10 \mu \mathrm{M})$ remain almost identical for three days of incubation (Figure 4a). On the contrary, the CD signals significantly decreased in the presence of a-synuclein monomers $(1 \mu \mathrm{M})$ after 3 days of incubation (Figure $4 \mathrm{~b}$ ), due to the precipitation of tau aggregates. It is also interesting to note that $\mathrm{a}$-synuclein filaments $(1 \mu \mathrm{M}$, monomer concentration) more effectively induce the formation of tau precipitates (Figure 4c). The tau aggregates were resuspended in solution and fluorescence was measured upon addition of ThT to the solution (Figure S8). The ThT fluorescence is greatly increased for the mixture of tau and $a$-synuclein filaments, suggesting that $a$-synuclein filaments promote tau aggregation more effectively than a-synuclein monomers.

\section{Cytotoxic properties of a-synuclein aggregates.}

Cytotoxic activities of a-synuclein aggregates formed in the absence and presence of tau were examined using mammalian neuroblastoma cells (SH-SY5Y). Pure a-synuclein and tau, and the mixtures of the two proteins incubated for 2 days at $37{ }^{\circ} \mathrm{C}$ were treated to the cells, and toxicity was measured by using MTT (3-(4,5-dimethylthiazol-2-yl)-2,5diphenyltetrazolium bromide) assay (Figure 5). The mixtures of the two proteins aged for 2 days under the experimental conditions in Figure 1 exhibit cytotoxic activities, while pure proteins show moderate (a-synuclein) and little toxicities (tau). After the two days of 
incubations, the mixtures form filamentous aggregates, as shown in Figure 2c and Figure S2, suggesting that filamentous aggregates have cytotoxic activities. Pure $a$-synuclein also exhibits moderate cytotoxicity at higher concentrations presumably due to the cytotoxic small oligomers present in the aged a-synuclein sample shown in Figure 2a.

\section{Distinct a-synuclein filaments formed in the presence of tau.}

There is mounting evidence that suggested a-synuclein behaves like a prion that can form distinct fibrillar aggregates (strains) with different molecular conformations. ${ }^{12,} 30,31,32$ In order to examine whether tau induces distinct a-synuclein aggregates, TEM was used to compare morphologies of the a-synuclein filaments formed in the absence and presence tau (Figure $6 \mathrm{a}$ and $6 \mathrm{~b}$ ). The TEM images clearly show that $\mathrm{a}$-synuclein forms distinct twisted thicker filaments with a diameter of $\sim 21 \mathrm{~nm}$ in the presence of tau (Figure S9), in comparison to those with a diameter of $\sim 10 \mathrm{~nm}$ in the absence of tau.

Solid-state NMR was used to compare structural features of the two a-synuclein filaments. Figure $6 \mathrm{c}$ shows ${ }^{13} \mathrm{C}-{ }^{13} \mathrm{C}$ correlation solid-state NMR spectra obtained with a dipolar assist rotational resonance (DARR) mixing scheme $(20 \mathrm{~ms})$. The two solid-state NMR spectra are overlapped well, suggesting that the two filaments have similar overall structural features. However, distinct NMR cross-peaks (* in Figure 6c) were also observed with different chemical shifts of the sidechains (Figure S10). The different chemical shifts indicate that the two a-synuclein filaments have distinct molecular conformations.

\section{Tau interacts with the C-terminal region of a-synuclein.}

Our combined analyses of co-aggregation of a-synuclein and tau showed that monomeric forms of tau promote a-synuclein aggregation. We used solution NMR spectroscopy to explore interactions between tau and a-synuclein monomers. Two-dimensional ${ }^{1} \mathrm{H} /{ }^{15} \mathrm{~N}$ heteronuclear single-quantum coherence (HSQC) NMR spectra were acquired for ${ }^{15} \mathrm{~N}$ labeled a-synuclein in the absence and presence of unlabeled tau (Figure 7a and Figure S11). In the overlaid HSQC NMR spectra, notable changes in the chemical shift were observed for numerous residues upon additions of tau monomers.

The chemical shift perturbations are more pronounced in the $\mathrm{C}$-terminal region of $\mathrm{a}$ synuclein (Figure $7 b)$. The $\mathrm{N}$-terminal regions $(15-63)$ are also slightly affected, while the non-amyloid- $\beta$ component (NAC) region (65 - 95) remains nearly unchanged. The titration NMR experiments indicate that tau affects both $\mathrm{N}$-terminal as well as $\mathrm{C}$-terminal regions of a-synuclein. The addition of tau also causes the NMR signal to decrease in intensity for the residues undergoing chemical shift changes (Figure S12). However, the decreases in the NMR signal intensity is observed only for the C-terminal region (110 - 140) of a-synuclein (Figure S12). These NMR results suggest that tau may selectively interact with the Cterminal region on intermediate time scales (millisecond to microsecond), while the $\mathrm{N}$ terminal region is not directly involved in the interaction with tau.

We measured amide backbone ${ }^{15} \mathrm{~N}$ transverse relaxation rates $\left(\mathrm{R}_{2}\right)$ of a-synuclein in the absence and presence of tau to assess the interactions between the proteins (Figure 7c). The transverse relaxation rates $\left(\mathrm{R}_{2}\right)$ of pure $\mathrm{a}$-synuclein are less than $8 \mathrm{~s}^{-1}$ at $15^{\circ} \mathrm{C}$, as was previously observed for disordered $\mathrm{a}$-synuclein. ${ }^{33,}{ }^{34} \mathrm{In}$ the presence of tau, the ${ }^{15} \mathrm{~N}$ 
relaxation rates sensitive to the intermediate time scales are greatly enhanced in the Cterminal region $(110-140)$, supporting the interaction between the C-terminal regions of asynuclein and tau. On the basis of the CD spectrum of the protein mixture in Figure S4, the two proteins remain as natively unfolded states in the mixture. Thus, the higher $\mathrm{R}_{2}$ values accompanied by the decreased NMR signal intensity of the C-terminal region indicate that the $\mathrm{C}$-terminal region of a-synuclein transiently interacts with tau on intermediate time scales rather than by conformational changes of a-synuclein.

\section{Discussion}

Co-incubation of the pathological proteins (a-synuclein and tau) was shown to promote mutual aggregation, which might be associated with co-occurrence of multiple neurodegenerative diseases in the same patient. Molecular basis of the synergistic aggregation has, however, not been clearly understood. In this report, we systematically investigated aggregation process of the mixtures of a-synuclein and tau with different protein concentrations using various biophysical techniques. Our combined analysis of asynuclein aggregation in the presence and absence of tau revealed that monomeric forms of tau accelerate the formation of a-synuclein filaments. $a$-synuclein monomers were also able to induce tau aggregation (Figure $4 \mathrm{~b}$ and $\mathrm{S} 6$ ) at the same experimental conditions.

Interestingly, filamentous aggregates of a-synuclein seeded tau aggregation more effectively than $a$-synuclein monomers (Figure $4 b$ and $4 c$ ). These results indicate that the composition of protein aggregates formed from the protein mixture depends on the molar ratio of the two proteins. For example, the TEM images and solid-state NMR spectrum in Figure 6 were acquired from the mixture at a-synuclein to tau molar ratio of 1:0.3. In particular, the filamentous aggregates used for the solid-state NMR spectrum were obtained using the doubly ${ }^{13} \mathrm{C} /{ }^{15} \mathrm{~N}$ labeled $\mathrm{a}$-synuclein $(70 \mu \mathrm{M})$ and unlabeled tau $(20 \mu \mathrm{M})$ and the signal to noise ratio of the spectrum was similar to that of pure a-synuclein filaments. In addition, a majority of the filaments in the TEM images are highly homogeneous (Figure S2) consistent with the relatively narrow linewidth of the NMR cross-peaks ( $0.7 \mathrm{ppm})$ (Figure S10) comparable to those from previously reported homogeneous amyloid fibrils $(0.6-1$

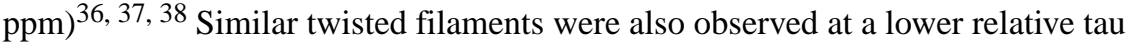
concentration (10\%), as shown in Figure S13. These results suggest that the twisted filamentous aggregates formed at the molar ratio of 1:0.3 mainly consist of a-synuclein. Synergistic interactions between a-synuclein and tau might lead to the distinct morphology and molecular conformation.

Our solution NMR results revealed that monomeric forms of tau selectively interact with the $\mathrm{C}$-terminal region of a-synuclein. The natively unfolded states of two proteins remain, however, largely unfolded as the native states in the mixture (Figure S4), suggesting that tau dose not induce major conformational changes of a-synuclein. Chemical shift perturbation by tau is also relatively small $(<0.1 \mathrm{ppm})$, and the dissociation constant $(\mathrm{Kd})$ of the interaction was estimated to be $8.1 \mu \mathrm{M} \pm 2.0 \mu \mathrm{M}$ (Figure S11). Thus, transient interactions between the two proteins appear to accelerate $a$-synuclein aggregation. Previous structural characterizations of a-synuclein demonstrated that the intrinsically disordered protein is partially stabilized by long-range interactions between the $\mathrm{N}$-terminal and $\mathrm{C}$-terminal regions of the protein. ${ }^{13,14,34,39}$ Disruption of the long-range contacts by single-point 
mutations (A30P and A53P) was shown to accelerate a-synuclein oligomerization. ${ }^{15}$ Deletion of the $\mathrm{C}$-terminal region was also shown to promote fibril formation of $\mathrm{a}$ synuclein, $40,41,42,43$ suggesting that the $\mathrm{C}$-terminal regions play a protective role in $\mathbf{a}$ synuclein aggregation. ${ }^{17,44,45}$ In addition, a bacterial endotoxin, lipopolysaccharide, was shown to interact with the $\mathrm{N}$-terminal region of a-synuclein, producing structurally distinct a-synuclein filaments. ${ }^{46}$

The two pathological proteins are highly charged at the physiological $\mathrm{pH}$, as shown in Figure S1. In particular, the C-terminal region of a-synuclein $(101-140)$ is highly negatively charged (pI, 3.4), while the central region of tau $(141-230)$ is positively charged (pI, 11.4) at the neutral $\mathrm{pH}$, suggesting the presence of electrostatic interactions between those regions. The electrostatic interactions may transiently disrupt the long-range interactions between the $\mathrm{N}$-terminal and $\mathrm{C}$-terminal regions. In addition, the positively charged tau may also reduce repulsive intermolecular interactions between the negatively charged C-terminal regions, facilitating intermolecular contacts between a-synuclein, and vice versa.

Our present study also reports that addition of tau promotes the formation of toxic asynuclein aggregates. More notably, the synergistic interaction induces quite distinct helical paired a-synuclein filaments (Figure 6) from previously reported a-synuclein filaments. $32,46,47$ a-synuclein is an intrinsically disordered protein that can adopt a variety of different molecular conformations. The conformational plasticity might lead to distinct asynuclein filamentous aggregates depending on the environment, ${ }^{30,31,48,49}$ linked to phenotype diversities of a-synucleinopathies.

In summary, we provided molecular basis for synergistic aggregations of a-synuclein and tau. The positively charged tau selectively interacts with the negatively charged C-terminal region of a-synuclein, which promotes the formation of cytotoxic paired helical a-synuclein filaments with distinct molecular conformations. a-synuclein monomers as well as fibrillar forms of a-synuclein can also induce tau aggregation. Finally, our combined analyses of synergistic aggregation of the two proteins can be extended to understand synergistic interactions between other pathological proteins including TAR-DNA-binding protein 43 (TDP-43) and a-synuclein. ${ }^{50}$

\title{
Supplementary Material
}

Refer to Web version on PubMed Central for supplementary material.

\section{ACKNOWLEDGMENT}

\author{
We thank Dr. Smet-Nocca (Université de Lille, Sciences et Technologies, France) for the tau plasmid. \\ Funding Sources \\ This work was supported in part by NIH grant (R01NS097490). A portion of this work was performed at the \\ National High Magnetic Field Laboratory, which is supported by the National Science Foundation Cooperative \\ Agreement No. DMR-1157490 and the State of Florida.
}




\section{ABBREVIATIONS}
NMR
nuclear magnetic resonance
TEM
transmission electron microscopy
CD
circular dichroism
ThT
thioflavin T
SDS-PAGE
sodium dodecyl sulfate-polyacrylamide gel electrophoresis
HSQC
heteronuclear single-quantum coherence

\section{REFERENCES}

1. Goedert M (2001) Alpha-synuclein and neurodegenerative diseases. Nat. Rev. Neurosci 2, 492-501. [PubMed: 11433374]

2. Ballatore C, Lee VM, and Trojanowski JQ (2007) Tau-mediated neurodegeneration in alzheimer's disease and related disorders. Nat. Rev. Neurosci 8, 663-672. [PubMed: 17684513]

3. Nonaka T, Masuda-Suzukake M, and Hasegawa M (2017) Molecular mechanisms of the codeposition of multiple pathological proteins in neurodegenerative diseases. Neuropathology.

4. Clinton LK, Blurton-Jones M, Myczek K, Trojanowski JQ, and LaFerla FM (2010) Synergistic interactions between abeta, tau, and alpha-synuclein: Acceleration of neuropathology and cognitive decline. J. Neurosci 30, 7281-7289. [PubMed: 20505094]

5. Irwin DJ, Lee VM, and Trojanowski JQ (2013) Parkinson's disease dementia: Convergence of alpha-synuclein, tau and amyloid-beta pathologies. Nat. Rev. Neurosci 14, 626-636. [PubMed: 23900411]

6. Moussaud S, Jones DR, Moussaud-Lamodiere EL, Delenclos M, Ross OA, and McLean PJ (2014) Alpha-synuclein and tau: Teammates in neurodegeneration? Mol. Neurodegener 9, 43-1326. [PubMed: 25352339]

7. Lippa CF, Fujiwara H, Mann DM, Giasson B, Baba M, Schmidt ML, Nee LE, O'Connell B, Pollen DA, St George-Hyslop P, Ghetti B, Nochlin D, Bird TD, Cairns NJ, Lee VM, Iwatsubo T, and Trojanowski JQ (1998) Lewy bodies contain altered alpha-synuclein in brains of many familial alzheimer's disease patients with mutations in presenilin and amyloid precursor protein genes. Am. J. Pathol 153, 1365-1370. [PubMed: 9811326]

8. Lippa CF, Schmidt ML, Lee VM, and Trojanowski JQ (1999) Antibodies to alpha-synuclein detect lewy bodies in many down's syndrome brains with alzheimer's disease. Ann. Neurol 45, 353-357. [PubMed: 10072050]

9. Hamilton RL (2000) Lewy bodies in alzheimer's disease: A neuropathological review of 145 cases using alpha-synuclein immunohistochemistry. Brain Pathol. 10, 378-384. [PubMed: 10885656]

10. Forman MS, Schmidt ML, Kasturi S, Perl DP, Lee VM, and Trojanowski JQ (2002) Tau and alphasynuclein pathology in amygdala of parkinsonism-dementia complex patients of guam. Am. J. Pathol 160, 1725-1731. [PubMed: 12000724]

11. Giasson BI, Forman MS, Higuchi M, Golbe LI, Graves CL, Kotzbauer PT, Trojanowski JQ, and Lee VM (2003) Initiation and synergistic fibrillization of tau and alpha-synuclein. Science. 300, 636-640. [PubMed: 12714745]

12. Guo JL, Covell DJ, Daniels JP, Iba M, Stieber A, Zhang B, Riddle DM, Kwong LK, Xu Y, Trojanowski JQ, and Lee VM (2013) Distinct alpha-synuclein strains differentially promote tau inclusions in neurons. Cell. 154, 103-117. [PubMed: 23827677]

13. Bernado P, Bertoncini CW, Griesinger C, Zweckstetter M, and Blackledge M (2005) Defining long-range order and local disorder in native alpha-synuclein using residual dipolar couplings. J. Am. Chem. Soc 127, 17968-17969. [PubMed: 16366524] 
14. Dedmon MM, Lindorff-Larsen K, Christodoulou J, Vendruscolo M, and Dobson CM (2005) Mapping long-range interactions in alpha-synuclein using spin-label NMR and ensemble molecular dynamics simulations. J. Am. Chem. Soc 127, 476-477. [PubMed: 15643843]

15. Bertoncini CW, Jung YS, Fernandez CO, Hoyer W, Griesinger C, Jovin TM, and Zweckstetter M (2005) Release of long-range tertiary interactions potentiates aggregation of natively unstructured alpha-synuclein. Proc. Natl. Acad. Sci. USA 102, 1430-1435. [PubMed: 15671169]

16. Bertoncini CW, Fernandez CO, Griesinger C, Jovin TM, and Zweckstetter M (2005) Familial mutants of alpha-synuclein with increased neurotoxicity have a destabilized conformation. J. Biol. Chem 280, 30649-30652. [PubMed: 16020550]

17. Fernandez CO, Hoyer W, Zweckstetter M, Jares-Erijman EA, Subramaniam V, Griesinger C, and Jovin TM (2004) NMR of alpha-synuclein-polyamine complexes elucidates the mechanism and kinetics of induced aggregation. EMBO J. 23, 2039-2046. [PubMed: 15103328]

18. Goedert M, Eisenberg DS, and Crowther RA (2017) Propagation of tau aggregates and neurodegeneration. Annu. Rev. Neurosci 40, 189-210. [PubMed: 28772101]

19. Gerson JE, Mudher A, and Kayed R (2016) Potential mechanisms and implications for the formation of tau oligomeric strains. Crit. Rev. Biochem. Mol. Biol 51, 482-496. [PubMed: 27650389]

20. Ghee M, Melki R, Michot N, and Mallet J (2005) PA700, the regulatory complex of the 26S proteasome, interferes with alpha-synuclein assembly. FEBS J 272, 4023-4033. [PubMed: 16098186]

21. Despres C, Byrne C, Qi H, Cantrelle FX, Huvent I, Chambraud B, Baulieu EE, Jacquot Y, Landrieu I, Lippens G, and Smet-Nocca C (2017) Identification of the tau phosphorylation pattern that drives its aggregation. Proc. Natl. Acad. Sci. U. S. A 114, 9080-9085. [PubMed: 28784767]

22. Delaglio F, Grzesiek S, Vuister GW, Zhu G, Pfeifer J, and Bax A (1995) NMRPipe: A multidimensional spectral processing system based on UNIX pipes. J. Biomol. NMR 6, 277-293. [PubMed: 8520220]

23. Johnson BA (2004) Using NMRView to visualize and analyze the NMR spectra of macromolecules. Methods Mol. Biol 278, 313-352. [PubMed: 15318002]

24. Takegoshi K, Nakamura S, and Terao T (2003) 13C-1H dipolar-driven 13C-13C recoupling without $13 \mathrm{C}$ rf irradiation in nuclear magnetic resonance of rotating solids. The Journal of Chemical Physics. 118, 2325-2341.

25. Fung BM, Khitrin AK, and Ermolaev K (2000) An improved broadband decoupling sequence for liquid crystals and solids. J. Magn. Reson 142, 97-101. [PubMed: 10617439]

26. Lashuel HA, Hartley D, Petre BM, Walz T, and Lansbury PT (2002) Neurodegenerative disease: Amyloid pores from pathogenic mutations. Nature. 418, 291.

27. Cremades N, Chen SW, and Dobson CM (2017) Structural characteristics of alpha-synuclein oligomers. Int. Rev. Cell. Mol. Biol 329, 79-143.

28. Sreerama N, and Woody RW (2000) Estimation of protein secondary structure from circular dichroism spectra: Comparison of CONTIN, SELCON, and CDSSTR methods with an expanded reference set. Anal. Biochem 287, 252-260. [PubMed: 11112271]

29. Ghosh D, Singh PK, Sahay S, Jha NN, Jacob RS, Sen S, Kumar A, Riek R, and Maji SK (2015) Structure based aggregation studies reveal the presence of helix-rich intermediate during alphasynuclein aggregation. Sci. Rep 5, 9228. [PubMed: 25784353]

30. Peelaerts W, Bousset L, Van der Perren A, Moskalyuk A, Pulizzi R, Giugliano M, Van den Haute C, Melki R, and Baekelandt V (2015) Alpha-synuclein strains cause distinct synucleinopathies after local and systemic administration. Nature. 522, 340-344. [PubMed: 26061766]

31. Peng C, Gathagan RJ, and Lee VM (2018) Distinct alpha-synuclein strains and implications for heterogeneity among alpha-synucleinopathies. Neurobiol. Dis 109, 209-218. [PubMed: 28751258]

32. Bousset L, Pieri L, Ruiz-Arlandis G, Gath J, Jensen PH, Habenstein B, Madiona K, Olieric V, Bockmann A, Meier BH, and Melki R (2013) Structural and functional characterization of two alpha-synuclein strains. Nat. Commun 4, 2575. [PubMed: 24108358]

33. Bussell R, and Eliezer D (2001) Residual structure and dynamics in parkinson's disease-associated mutants of alpha-synuclein. J. Biol. Chem 276, 45996-46003. [PubMed: 11590151] 
34. Bai J, Cheng K, Liu M, and Li C (2016) Impact of the alpha-synuclein initial ensemble structure on fibrillation pathways and kinetics. J Phys Chem B 120, 3140-3147. [PubMed: 26950519]

35. Bodner CR, Maltsev AS, Dobson CM, and Bax A (2010) Differential phospholipid binding of alpha-synuclein variants implicated in parkinson's disease revealed by solution NMR spectroscopy. Biochemistry. 49, 862-871. [PubMed: 20041693]

36. Daebel V, Chinnathambi S, Biernat J, Schwalbe M, Habenstein B, Loquet A, Akoury E, Tepper K, Muller H, Baldus M, Griesinger C, Zweckstetter M, Mandelkow E, Vijayan V, and Lange A (2012) Beta-sheet core of tau paired helical filaments revealed by solid-state NMR. J. Am. Chem. Soc 134, 13982-13989. [PubMed: 22862303]

37. Debelouchina GT, Platt GW, Bayro MJ, Radford SE, and Griffin RG (2010) Magic angle spinning NMR analysis of beta2-microglobulin amyloid fibrils in two distinct morphologies. J. Am. Chem. Soc 132, 10414-10423. [PubMed: 20662519]

38. Helmus JJ, Surewicz K, Surewicz WK, and Jaroniec CP (2010) Conformational flexibility of Y145Stop human prion protein amyloid fibrils probed by solid-state nuclear magnetic resonance spectroscopy. J. Am. Chem. Soc 132, 2393-2403. [PubMed: 20121096]

39. Wu KP, Kim S, Fela DA, and Baum J (2008) Characterization of conformational and dynamic properties of natively unfolded human and mouse alpha-synuclein ensembles by NMR: Implication for aggregation. J. Mol. Biol 378, 1104-1115. [PubMed: 18423664]

40. Murray IV, Giasson BI, Quinn SM, Koppaka V, Axelsen PH, Ischiropoulos H, Trojanowski JQ, and Lee VM (2003) Role of alpha-synuclein carboxy-terminus on fibril formation in vitro. Biochemistry. 42, 8530-8540. [PubMed: 12859200]

41. Serpell LC, Berriman J, Jakes R, Goedert M, and Crowther RA (2000) Fiber diffraction of synthetic alpha-synuclein filaments shows amyloid-like cross-beta conformation. Proc. Natl. Acad. Sci. U. S. A 97, 4897-4902. [PubMed: 10781096]

42. Crowther RA, Jakes R, Spillantini MG, and Goedert M (1998) Synthetic filaments assembled from C-terminally truncated alpha-synuclein. FEBS Lett. 436, 309-312. [PubMed: 9801138]

43. Hoyer W, Cherny D, Subramaniam V, and Jovin TM (2004) Impact of the acidic C-terminal region comprising amino acids 109-140 on alpha-synuclein aggregation in vitro. Biochemistry. 43, 16233-16242. [PubMed: 15610017]

44. Eliezer D (2013) The mysterious C-terminal tail of alpha-synuclein: Nanobody's guess. J. Mol. Biol 425, 2393-2396. [PubMed: 23541591]

45. Li W, West N, Colla E, Pletnikova O, Troncoso JC, Marsh L, Dawson TM, Jakala P, Hartmann T, Price DL, and Lee MK (2005) Aggregation promoting C-terminal truncation of alpha-synuclein is a normal cellular process and is enhanced by the familial parkinson's disease-linked mutations. Proc. Natl. Acad. Sci. U. S. A 102, 2162-2167. [PubMed: 15684072]

46. Kim C, Lv G, Lee JS, Jung BC, Masuda-Suzukake M, Hong CS, Valera E, Lee HJ, Paik SR, Hasegawa M, Masliah E, Eliezer D, and Lee SJ (2016) Exposure to bacterial endotoxin generates a distinct strain of alpha-synuclein fibril. Sci. Rep 6, 30891. [PubMed: 27488222]

47. Tuttle MD, Comellas G, Nieuwkoop AJ, Covell DJ, Berthold DA, Kloepper KD, Courtney JM, Kim JK, Barclay AM, Kendall A, Wan W, Stubbs G, Schwieters CD, Lee VM, George JM, and Rienstra CM (2016) Solid-state NMR structure of a pathogenic fibril of full-length human alphasynuclein. Nat. Struct. Mol. Biol 23, 409-415. [PubMed: 27018801]

48. Peng C, Gathagan RJ, Covell DJ, Medellin C, Stieber A, Robinson JL, Zhang B, Pitkin RM, Olufemi MF, Luk KC, Trojanowski JQ, and Lee VM (2018) Cellular milieu imparts distinct pathological alpha-synuclein strains in alpha-synucleinopathies. Nature. 557, 558-563. [PubMed: 29743672]

49. Kumar H, Singh J, Kumari P, and Udgaonkar JB (2017) Modulation of the extent of structural heterogeneity in alpha-synuclein fibrils by the small molecule thioflavin T. J. Biol. Chem 292, 16891-16903. [PubMed: 28760825]

50. Higashi S, Iseki E, Yamamoto R, Minegishi M, Hino H, Fujisawa K, Togo T, Katsuse O, Uchikado H, Furukawa Y, Kosaka K, and Arai H (2007) Concurrence of TDP-43, tau and alpha-synuclein pathology in brains of alzheimer's disease and dementia with lewy bodies. Brain Res. 1184, 284294. [PubMed: 17963732] 


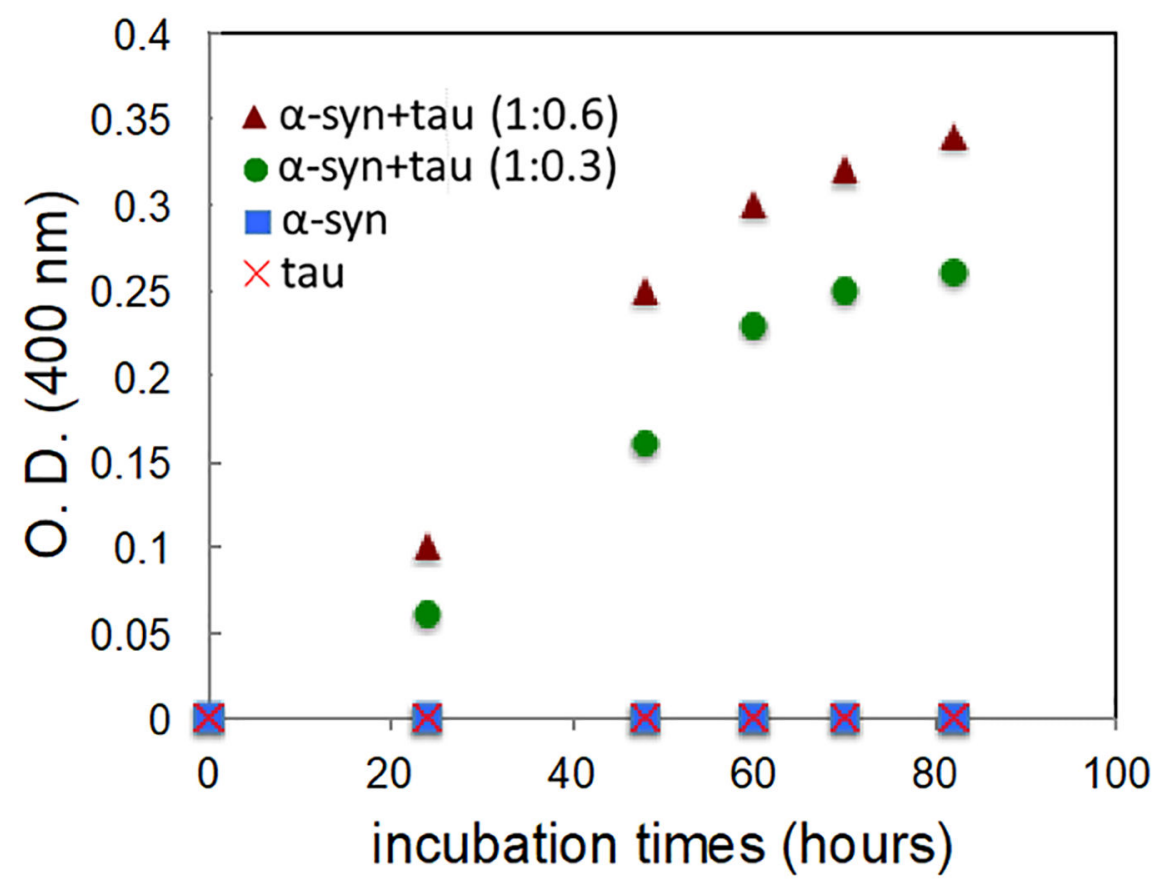

Figure 1.

Aggregation kinetics of $a$-synuclein $(0.75 \mathrm{mg} / \mathrm{ml}, 50 \mu \mathrm{M}$, circle), tau (1.5 mg/ml, $30 \mu \mathrm{M}, \times)$, and mixtures of a-synuclein and tau $(50 \mu \mathrm{M}$ and $15 \mu \mathrm{M}, 1: 0.3$, square; $50 \mu \mathrm{M}$ and $30 \mu \mathrm{M}$, 1:0.6, triangle). Optical density (O. D.) was measured at $400 \mathrm{~nm}$ for turbidity of the samples. The accelerated aggregation kinetics was also observed at different protein concentrations (70 $\mu \mathrm{M}$ and $20 \mu \mathrm{M}$ for $\mathrm{a}$-synuclein and tau, respectively). 

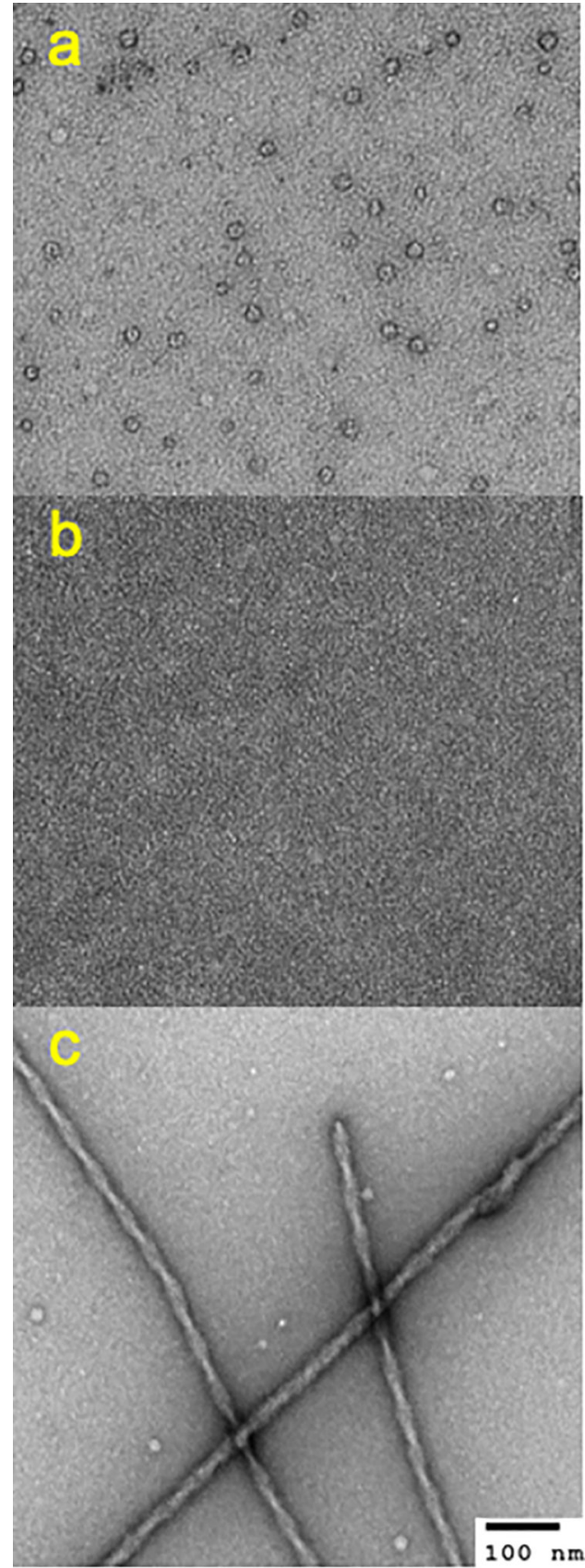

Figure 2.

TEM images of the pure a-synuclein (a), pure tau (b), and a mixture of a-synuclein and tau (1:0.3) (c) incubated for 1 day at $37^{\circ} \mathrm{C}$ in $10 \mathrm{mM}$ phosphate buffer (pH 7.4). The protein samples used for the aggregation kinetics in Figure 1 were used to acquire the TEM images. 

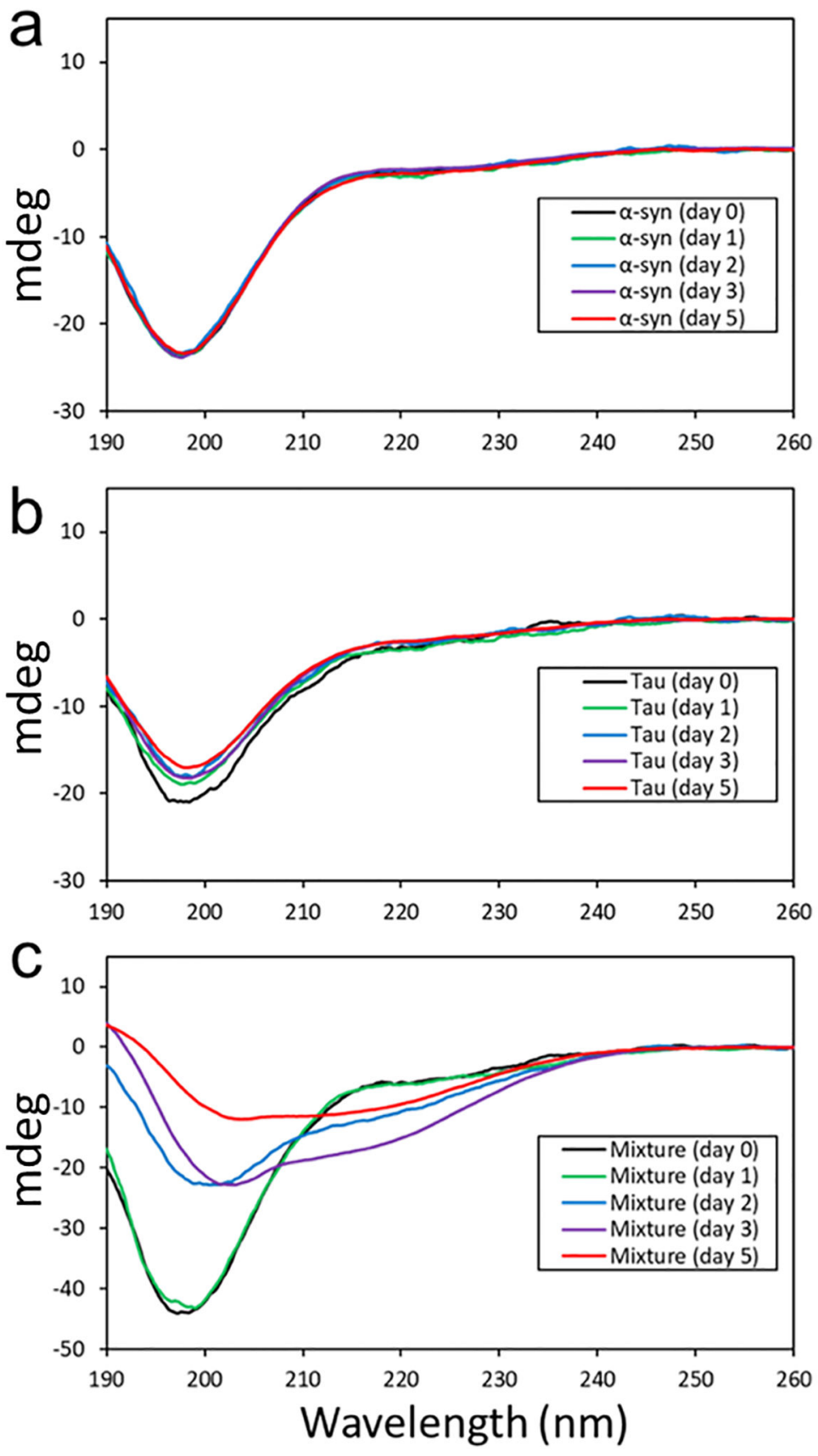

Figure 3.

CD spectra of pure a-synuclein $(10 \mu \mathrm{M})(\mathrm{a})$, pure tau $(3 \mu \mathrm{M})(\mathrm{b})$, and a mixture of $\mathrm{a}$ synuclein $(10 \mu \mathrm{M})$ and tau $(3 \mu \mathrm{M})(\mathrm{c})$ acquired at different incubation times. The CD signal of the mixture after 5 days of incubation decreased due to the precipitation of the protein aggregates. 

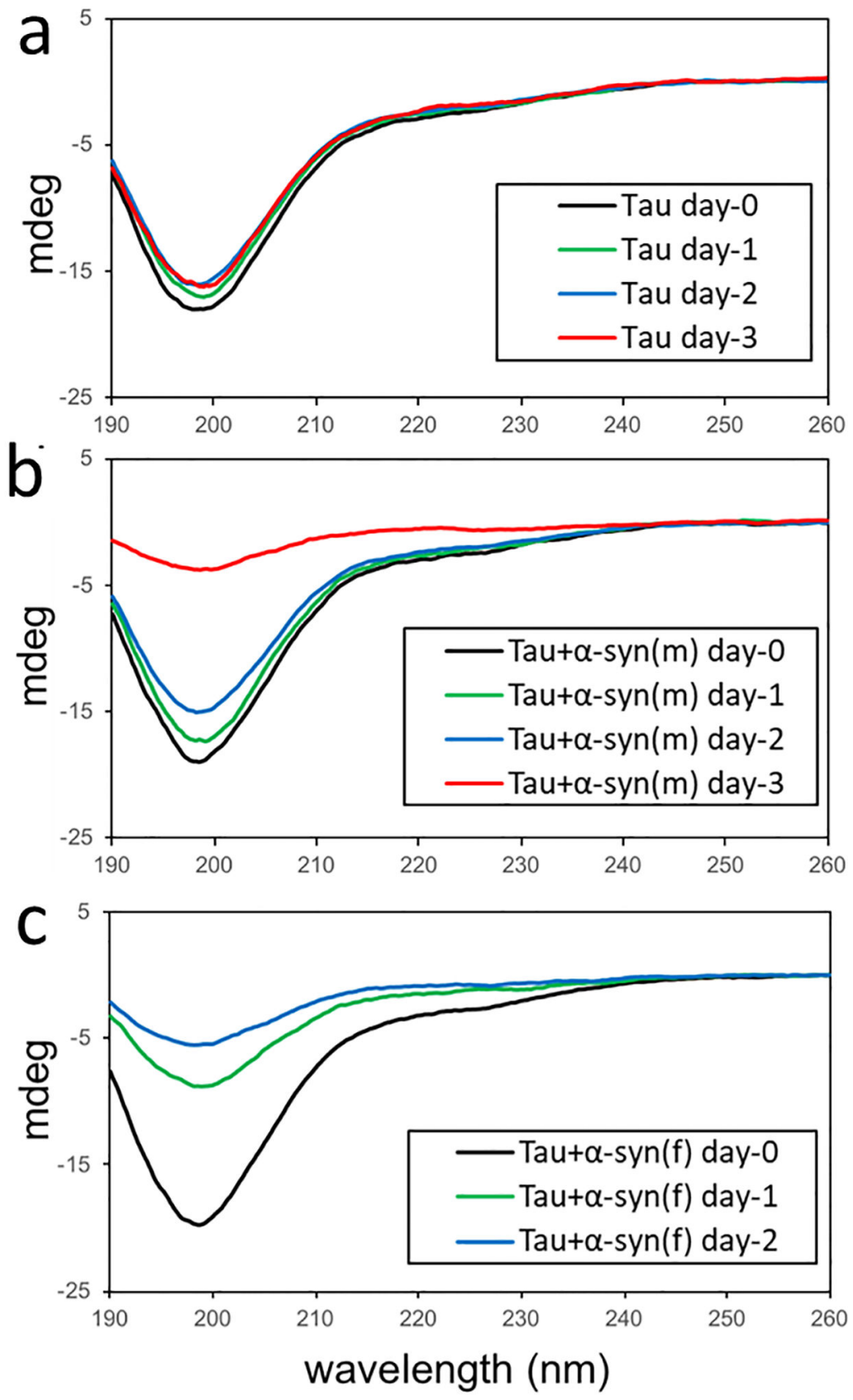

Figure 4.

CD spectra of pure tau $(10 \mu \mathrm{M})(\mathrm{a})$, a mixture of tau $(10 \mu \mathrm{M})$ and $\mathrm{a}$-synuclein monomer (1 $\mu \mathrm{M})(\mathrm{b})$, and a mixture of tau $(10 \mu \mathrm{M})$ and a-synuclein filaments $(1 \mu \mathrm{M}$, monomer concentration) (c) acquired at different incubation times. The CD signal of the mixtures decreased due to the precipitation of the protein aggregates. 


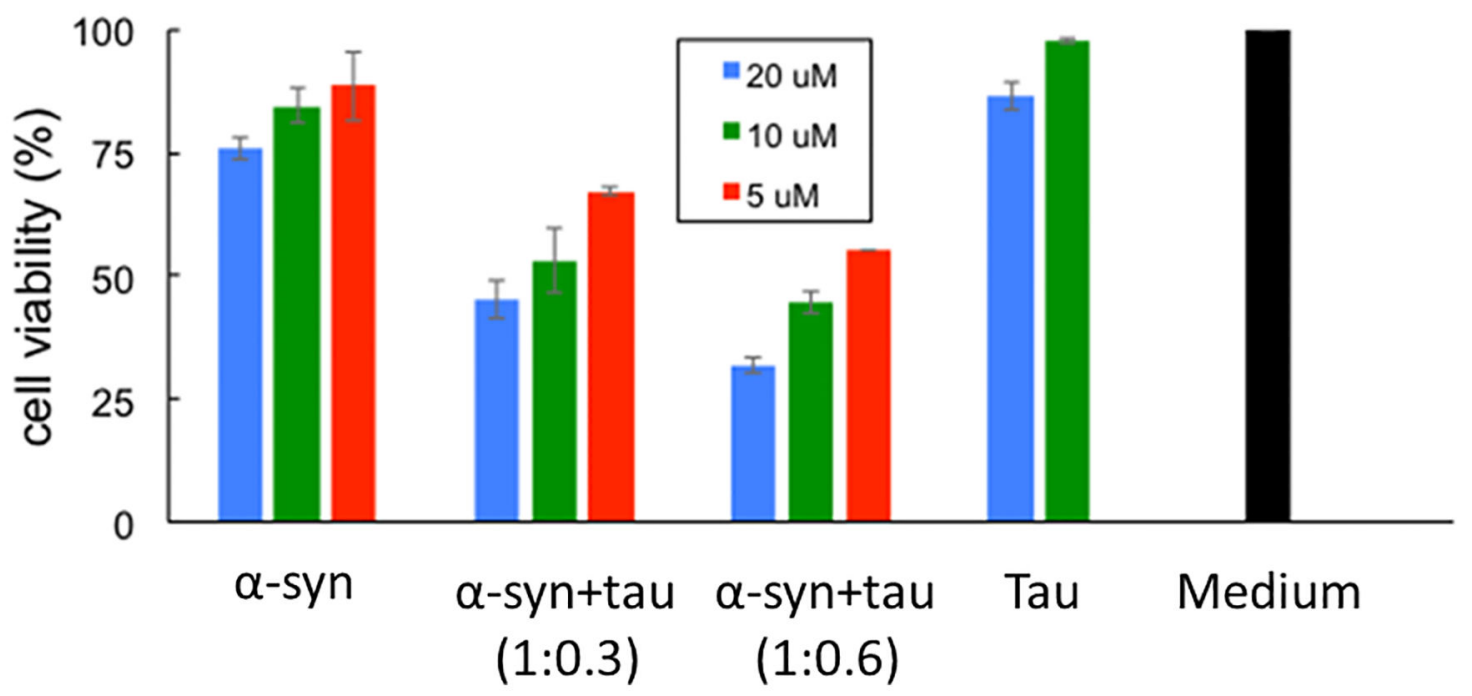

Figure 5.

MTT assay for pure a-synuclein, pure tau and mixtures of a-synuclein and tau at different concentrations (monomer concentration). The protein samples ( $\mathrm{pH}$ 7.4) aged for two days under the experimental conditions used in the aggregation kinetics in Figure 1 were treated to the mammalian cells, and the cell viability was calculated by measuring the absorbance of the cell solution at $570 \mathrm{~nm}$ after $24 \mathrm{hrs}$ of the treatment. 

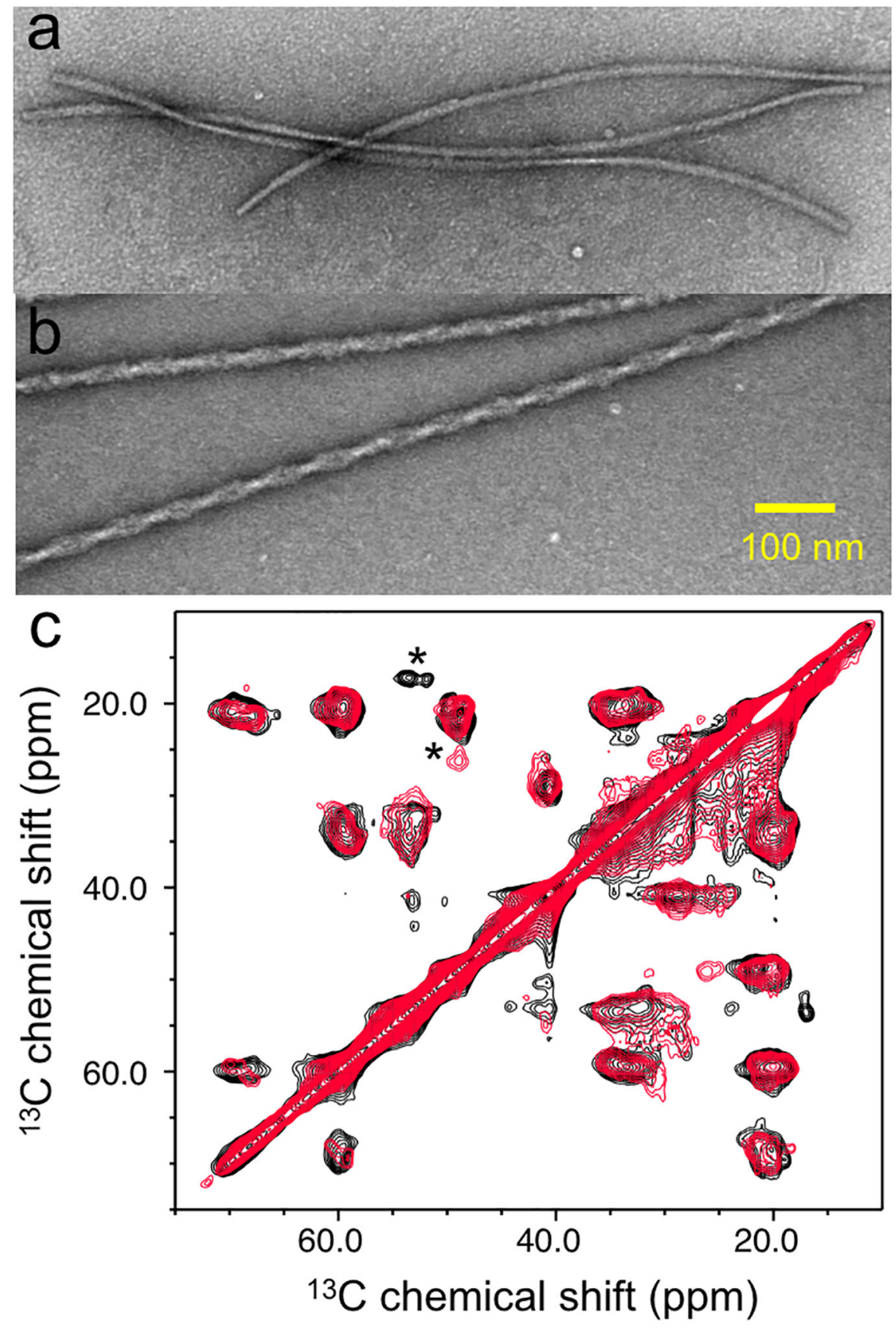

Figure 6.

TEM images of the pure $a$-synuclein $(210 \mu \mathrm{M})$ (a) and mixtures of $a$-synuclein $(70 \mu \mathrm{M})$ and tau $(20 \mu \mathrm{M})$ at a molar of 1:0.3 (b). The pure $\mathrm{a}$-synuclein and mixture of the two proteins were incubated at $37{ }^{\circ} \mathrm{C}$ for one week and one day, respectively. (c) $2 \mathrm{D}{ }^{13} \mathrm{C}-{ }^{13} \mathrm{C}$ correlation solid-state NMR spectra for the a-synuclein filaments formed in the absence (black) and presence (red) of tau. 

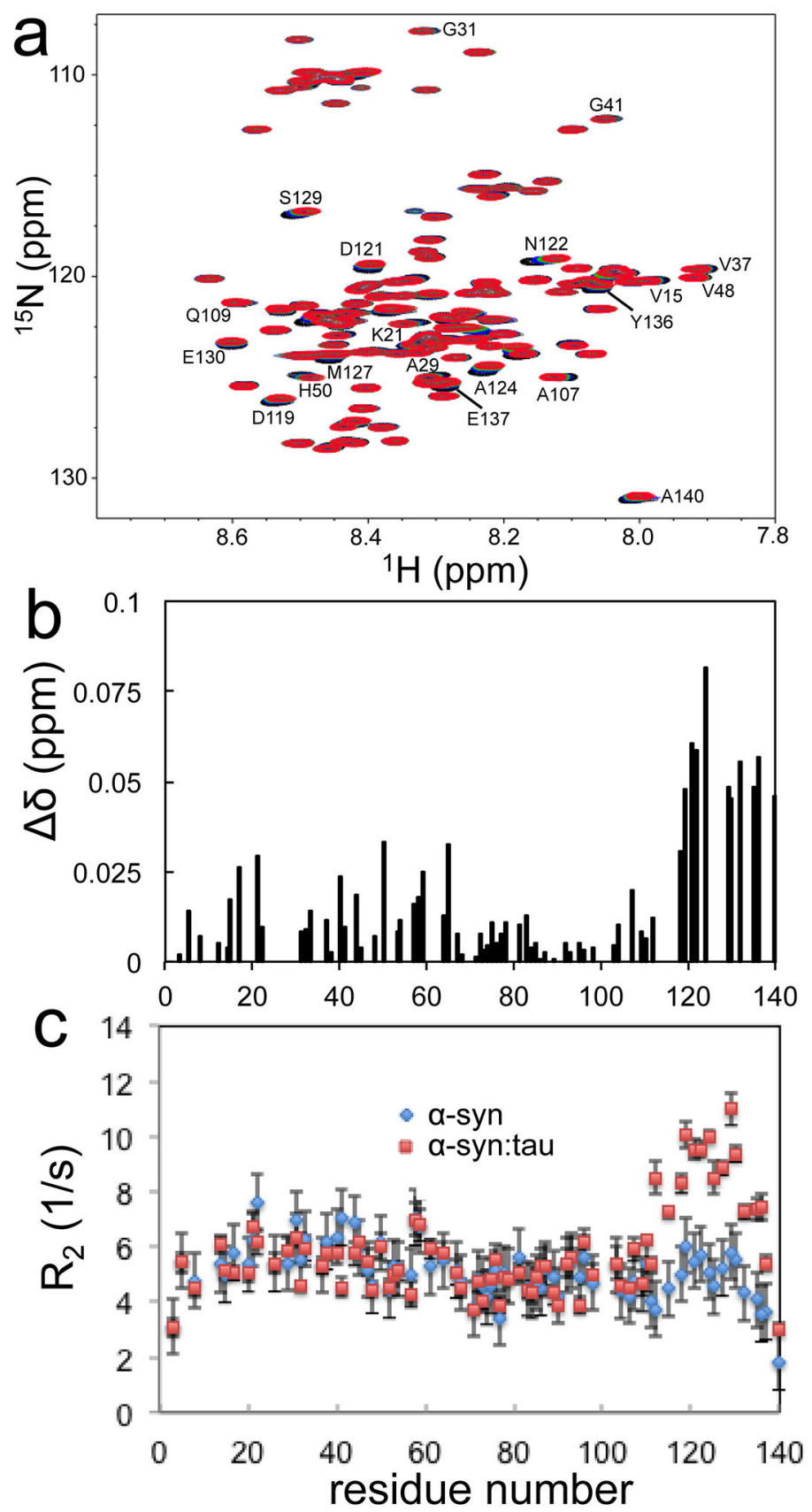

Figure 7.

(a) Overlaid ${ }^{1} \mathrm{H} /{ }^{15} \mathrm{~N}$ HSQC NMR spectra of a-synuclein $(70 \mu \mathrm{M}, \mathrm{pH} 7.4$, black) and tau $\left(140 \mu \mathrm{M}\right.$, red) at $15{ }^{\circ} \mathrm{C}$. (b) Weighted sum of the ${ }^{1} \mathrm{H}$ and ${ }^{15} \mathrm{~N}$ Chemical shift changes of $\mathrm{a}$ synuclein $(70 \mu \mathrm{M})$ upon addition of tau $(140 \mu \mathrm{M}), \Delta \delta=\sqrt{\delta_{H}^{2}+0.2 \delta_{N^{*}}^{2}}$ (c) Transverse relaxation rates $\left(\mathrm{R}_{2}\right)$ of a-synuclein $(70 \mu \mathrm{M})$ in the absence (diamond) and presence of tau $\left(140 \mu \mathrm{M}\right.$, rectangle) recorded at $15^{\circ} \mathrm{C}$. All of the NMR spectra were collected at a proton frequency of $800 \mathrm{MHz}$. Backbone assignment was made from previous resonance 
assignments available in the Biological Magnetic Resonance Data Bank (BMRB 16543) ${ }^{35}$ and 3D NMR experiments. 